\title{
Análise de transformações da técnica em Medicina: reflexões sobre uma proposta metodológica*
}

Ana Sílvia Whitaker Dalmaso ${ }^{1}$

DALMASO, A. S. W. An analysis of the transformations of medical technique: reflexions about a proposal, Interface _ Comunicação, Saúde, Educação, v.4 , n.6, 2000.

This study deals with the conformation of contemporary Medicine as a historical and social practice, whose technique has been profoundly influenced not only by scientific knowledge, but by scientific rationality as well. To study this articulation, the viewpoint adopted was one oriented to sound practice. An analysis of data from renowned medical treatises and scientific journals published in the second half of the twentieth century revealed that clinical practice went through a transition process during this period. A comparison of several decades (the fifties, seventies and nineties) showed that an evolutionary process was at play, involving a great deal of tension as regards indicators of what "good physician performance" consists of. Concerning medical practice indicators, it became evident that a major technical change took place, consisting of a shift away from personal clinical experience and the relatively widespread production of research connected with clinical practice, toward the enhancement of a scientific set of procedures, submitted to efficiency and results testing, and the growth of specialized research centers. clinical practice, a technique that is close to the patient but that remains something of an art, a type of work both operative and unique, which applies science to individual care and which is committed to action, has become progressively strained due to a bias favoring greater theoretical and scientific knowledge.

KEY WORDS: $20^{\text {th }}$ century medical history; medical technology; knowledge, attitudes; practice; professional practice.

Este texto trata da conformação da Medicina contemporânea como prática histórica e social, cuja técnica vem sendo penetrada de forma crescente não só pelo conhecimento, mas pela racionalidade científica. O ângulo eleito para apreender esta articulação foi o das orientações para a boa prática. Mediante levantamento de informações nas publicações consagradas de tratados médicos e revistas científicas, feito na segunda metade do século XX, delineou-se o padrão transitivo da Clínica no período. A comparação entre períodos (anos 50, 70 e 90) possibilitou o reconhecimento de um movimento processual, com muitas tensões nas indicações para o bom desempenho do médico. Constatou-se, no plano das orientações para a prática, uma variação técnica importante, caracterizada pelo deslocamento da experiência clínica pessoal e da produção relativamente disseminada de pesquisa associada à assistência para a valorização do respaldo científico dos procedimentos, submetidos a testes de eficácia e de resultados, e para a ampliação de centros especializados em pesquisa. A Clínica, técnica desenvolvida na proximidade do doente e da arte, trabalho operacional e singular, que aplica a ciência na assistência individual e está comprometida com a ação, vem sendo progressivamente retesada por seu pólo de conhecimento mais teórico e científico.

PALAVRAS-CHAVE: história da Medicina do século 20; tecnologia médica; conhecimentos, atitudes; práticas; prática profissional.

\footnotetext{
* Este texto baseia-se nos resultados de pesquisas desenvolvidas pela autora, com a colaboração valiosa do Dr. Ricardo Bruno MendesGonçalves e da Prof. Dra. Lilia Blima Schraiber.

${ }^{1}$ Médica do Centro de Saúde-Escola Samuel B. Pessoa, Professora do Departamento de Medicina Preventiva da Faculdade de Medicina da Universidade de São Paulo. E-mail csesbp@org.usp.br
} 


\section{Introdução}

Para começar a tratar deste assunto, das transformações da técnica em Medicina, é necessário esclarecer a que se atribui as variações e o que se entende por técnica e os seus conexos, tecnologia e tecnológico.

A forma corrente de se interpretar mudanças é a teoria do progresso, que considera que há um motor inerente à história que suscita transformações e que o que é novo é melhor do que o anterior. E a Medicina é objeto de uma série de estudos deste tipo, que explicam como foi melhorando o diagnóstico e como homens engenhosos fizeram descobertas e desenvolveram equipamentos para exames subsidiários e para terapêutica (para o caso da hipertensão arterial, ver Dustan, 1997; Frohlich, 1997).

Uma outra maneira de interpretar as transformações, e contar a história, é aquela que atribui as modificações às condições complexas de vida que determinam tensões e soluções temporárias (Canguilhem, 1977; Entralgo, 1978; Cid, 1985). Em determinada situação convivem uma série de alternativas e personagens e, conforme as necessidades e estratégias históricas e sociais, predomina uma em detrimento de outra. Esta concepção não pode considerar que o que vem depois é melhor do que o anterior, ou seja, não há um progresso contínuo em uma determinada direção, mas respostas consideradas mais adequadas para as necessidades colocadas, em uma conjugação de fatores dinâmicos. Portanto, deste ângulo de interpretação, as transformações da Medicina são históricas (MendesGonçalves, 1979): o diagnóstico das doenças modificou-se no sentido de uma localização mais radical no corpo do homem, do órgão ao gene, e o conhecimento acumulado nesta direção desdobrou-se em técnicas de investigação mais restritivas e aprofundadas no corpo e técnicas de intervenção que têm como alvo principal a causa imediata.

Sobre o que vamos estar denominando técnica/tecnologia e tecnológico, há também duas interpretações polares. De um lado, a concepção mais corrente, que toma a tecnologia como arsenal material e a técnica como modo de operar o tecnológico, e que costuma adotar a primeira concepção de história exposta acima, explicando as transformações da tecnologia como progresso. Esta interpretação é usada com freqüência para dar conta de chamadas insuficiências de meios diagnósticos e terapêuticos em determinados momentos, vencidas quando "aparecem" os recursos como, por exemplo, os antibióticos e a endoscopia.

De outro lado, este conceito pode ser recolocado de forma mais ampliada, abrangendo a tecnologia material e a não material, sendo que esta última envolve tanto o conhecimento que instrui a ação, como as formas de operação não baseadas imediatamente em substrato material, como o contato interpessoal e a comunicação. A técnica, por sua vez, é concebida como "modo de fazer" (Novaes, 1996) não só segundo as características do recurso material, mas conforme as necessidades que tornaram aquela intervenção almejada, necessidades articuladas às formas de viver (MendesGonçalves, 1992). Se a técnica no mundo moderno foi largamente subsidiada pelo conhecimento científico, com a hipertrofia do pólo tecnológico material, a ciência, como produto do trabalho humano, também está vinculada às necessidades que colocaram os problemas a serem objeto 
de estudo (Mendes-Gonçalves, 1997).

Estudando a história da Medicina no século XIX (Dalmaso, 1991), e especialmente o diagnóstico e cuidado da pneumonia, constata-se que os médicos eram orientados (nos cursos e livros) a diagnosticar se o quadro era ou não típico e, na primeira alternativa, não intervir, porque se considerava que a natureza tinha a sua própria forma de resolução e que uma alteração do curso natural da doença podia fazer mais mal do que bem para o doente. Com esta concepção de natureza, de doença e do papel da Medicina, simplesmente não havia necessidade de tratamento no sentido mais restritivo que hoje damos a este termo, mas de cuidado como suporte (alimentação, sossego, ares benéficos) que pudesse contribuir para promover a força do doente no seu combate contra a doença. Aquelas concepções começaram a mudar no início do século XX, com uma valorização da contraposição homem-natureza em diversos campos da vida e do conhecimento, quando dispor de recursos que pudessem "cortar" a evolução da doença começa a ser tomado como necessário e, portanto, pesquisado.

A não disponibilidade de determinado recurso terapêutico não pode ser considerada como uma insuficiência da técnica, mas deve ser analisada conforme as necessidades do momento, relacionadas com as formas mais amplas de viver, curar e morrer (Canguilhem, 1982), às quais a técnica responde (Ortega, 1963). Considerar os antibióticos como necessários para a Medicina de todas as épocas é interpretar o passado com os pressupostos do presente, erro grave de análise (Loraux, 1992).

Análise de transformações: relações entre passado e futuro

Para analisar transformações é necessário estabelecer relações entre momentos diversos, um antes e um depois, cuja comparação permite reconhecer uma variação. Estamos, portanto, trabalhando sobre a noção de tempo e história. Cabe aqui logo um reparo à concepção de passado, presente e futuro. A interpretação mais corrente é aquela que os considera de forma estanque; uma outra é a que encontra no presente formas passadas e futuras, alterando-se só relativamente entre os tempos a sua densidade. Nesta segunda maneira de se explicar o tempo, formas passadas continuam coexistindo no futuro, o qual por sua vez foi gestado no passado (De Certeau, 1982; Veyne, 1983).

Reconhecer transformações no passado na nossa opinião tem diversas finalidades. Em primeiro lugar, costuma ser usado para alimentar uma erudição que nos dias de hoje está cada vez mais relegada ao supérfluo. Em segundo lugar, saber "da onde viemos" dá respaldo ao nosso trabalho, esclarecendo compromissos e limites. Em terceiro lugar, nos instrumentaliza a identificar tendências, o que é especialmente importante para aqueles que trabalham com ensino (Schraiber, 1989) e propõem pesquisa. Mas há ainda uma quarta finalidade, esta de natureza mais técnico-política, de reconhecer que o que parece hoje tão sólido pode também se

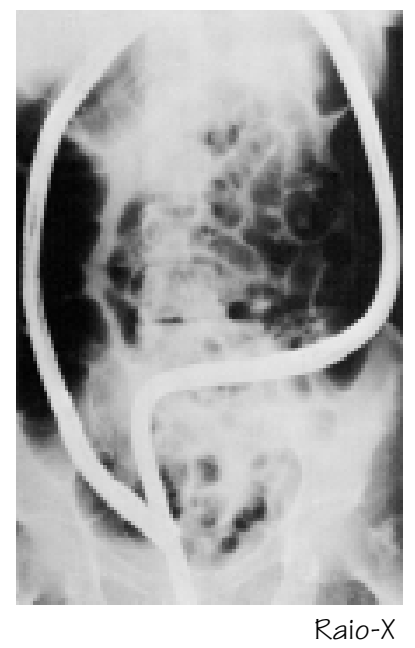

fevereiro, 2000 
desmanchar no ar, e de identificar brechas de transformação, que possibilitam apostar em determinadas alternativas, aquelas que possam responder melhor aos nossos projetos de vida e de humano.

A partir dessas considerações mais gerais, vamos delimitar o campo sobre o qual trabalharemos neste texto. De um lado, o foco é um campo específico, o da Medicina, não só de aplicação do quadro teórico de referência, mas também de elementos da realidade que subsidiaram a teoria, no ir e vir necessário entre um plano e outro. De outro, vamos apresentar uma metodologia de pesquisa e resultados que podem inspirar outros campos de pesquisa que tratem de objetos assemelhados. Tem-se ainda aquela ambição técnico-política, de buscar brechas no passado que possam orientar formas de conceber e cuidar da saúde não só progressistas, mas mais democráticas.

Temos acumulado um estudo abrangente de transformações da prática médica que abarca os períodos 1860-1910 (Dalmaso, 1991) e 1950-1990 (Dalmaso, 1998). Optamos por centrar esta exposição mais na segunda metade do século $X X$, por sua maior proximidade com os leitores, atualidade do passado em foco e porque neste período pode-se constatar a constituição da prática médica de base científica. A eleição de momentos de concentração de mudanças facilita o trabalho de pesquisa, uma vez que torna mais visível o contraste entre elementos comparados.

\section{Desenvolvimento de estudos}

A fonte principal de dados com que trabalhamos foram tratados médicos publicados no período ${ }^{2}$, acoplando-se artigos e editoriais de revista médica ${ }^{3}$.

A Medicina contemporânea tem o seu saber sedimentado em dois tipos principais de base, a escrita $e$ a oral, as quais constituem as duas formas maiores de transmissão do seu conteúdo, responsáveis pela sua reprodução a longo prazo.

Além dos textos das ciências médicas, que servem de base para a Clínica, a sistematização da tecnologia médica encontra-se formalmente em tratados médicos (Davis, 1978), aos quais se somam os manuais, voltados mais imediatamente para o trabalho, e em revistas especializadas, que congregam a divulgação de novas informações, retificando ou ratificando o conhecimento acumulado e expressando opiniões nos seus editoriais e cartas de leitores.

As edições mais recentes dos tratados médicos têm como conteúdo básico uma definição normativa da doença, informações sobre anatomia $e$ fisiologia da doença e, especialmente, tecnologia médica, os modos de fazer o diagnóstico $e$ instituir a terapêutica. Mas os tratados também tiveram uma variação, do registro de aulas dadas por professores nas academias de Medicina, percorrendo um número limitado de problemas (Graves, 1862; Jaccoud, 1869), ao texto sistematizado de informações sobre a doença para instruir o estudante e o trabalho do médico. Na língua inglesa, o primeiro texto sistemático sobre o conjunto das doenças e publicado com o formato que se mantém mais ou menos até hoje foi o de Osler, em 1892; em 1927, começou a ser publicado um tratado escrito não só por um autor, mas por um conjunto de especialistas ( $A$ text-book of medicine by American authors), coordenado inicialmente por Cecil, cujas edições sucessivas têm

\footnotetext{
${ }^{2}$ As edições sucessivas do Tratado de Medicina Interna (que teve variações na sua denominação), editadas inicialmente por CECIL, foram publicadas em 1927, 1930, 1933, 1940, 1943, 1947, 1951, 1955, 1959, 1963, 1967, 1971, 1975, 1979, 1982, 1985, 1988, 1992, 1996. A biblioteca da Faculdade de Medicina da Universidade de São Paulo dispõe das seguintes edições em inglês: 1947, 1955, 1963, 1971 e todas as sucessivas. Dos anos 50,70 e 90 foram lidos ao todo 42 textos, entre capítulos gerais sobre medicina e sobre algumas patologias específicas.
}

\footnotetext{
${ }^{3}$ Em 1828, a revista científica Boston Medical Inteeligencer é substituída pela Boston Medical and Surgical Journal que, por sua vez, em 1928, no volume 198, dá lugar à The New England Journal of Medicine. Na Biblioteca da Faculdade de Medicina da Universidade de São Paulo, a coleção (quase completa) começa com a publicação de 1839 . Dos anos 50, 70 e 90 foram lidos 90 textos, entre editoriais, discussão de casos clínicos e artigos sobre características do trabalho e sobre aspectos de determinadas doenças.
} 
servido como referência para a maior parte dos estudantes nas Américas.

Se os livros de Clínica fazem um compilado do saber positivo e geral do comportamento das doenças nos doentes, bastante próximo da ciência (patologia), e das formas correspondentes de identificá-las e tratá-las, no último quartel do século $\mathrm{XX}$ há um novo tipo de texto para o médico, as rotinas e protocolos. O método de trabalho centrado em protocolos teria como vantagens eliminar as influências "externas" à Medicina e à Ciência $e$ controlar a subjetividade, garantindo uma prática com menos incertezas e erros (Ribeiro, 1995), e fornecendo subsídios para controle de custos e da qualidade da assistência (Logan \& Scott, 1996). Eles representam instrumentos não materiais de trabalho, conjuntos estruturados de problemas (queixas, sinais, condições de risco) e de soluções (diagnósticas e terapêuticas) que auxiliam a atuação e a tomada de decisão pelo médico.

As rotinas são primordiais para a técnica, orientando o profissional no desempenho do seu trabalho (Ribeiro, 1995). No entanto, a especificidade da Medicina contemporânea é a de desenvolver e adotar procedimentos respaldados pela pesquisa científica, homogeneizando e tornando rotineira a assistência. A norma sobrepõe-se ao caso, estreitando-se a relação entre a técnica e a ciência. Os guidelines despontam como um novo tipo de literatura médica, recurso importante para sistematização e orientação para o que se considera uma boa prática, instrumentos também utilizados pela Medicina baseada em evidências científicas (Sackett et al., 1997).

A partir do levantamento de fontes de informação sobre o tema, há que se estabelecer uma metodologia de leitura que possa levar à identificação de "padrões de orientação" para o trabalho médico. Uma forma de coleta do material que nos parece produtiva é a técnica de descrição para cada tópico eleito, visando a construção de padrões. A análise do material escrito compondo uma série temporal fornece informações sobre evoluções $e$ permite explorar tendências. Os estudos comparativos permitem ultrapassar o caso singular, possibilitando a constituição de regularidades ou de constantes entre vários momentos ou espaços, podendo-se analisar semelhanças e dessemelhanças (Bruyne et al., 1977). Neste tipo de estudo o pesquisador usa uma forma de "raciocínio homológico", focalizando não os próprios dados empíricos, mas as suas propriedades e a relação entre estas propriedades. As comparações no tempo permitem estudar os próprios processos de mudança em suas diversas fases interdependentes.

A informação (de realidade produzida) que fornece o dado (de pesquisa) a ser comparado sofre um processo de formalização, no qual os traços secundários são mais ou menos abandonados, permitindo uma maior proeminência dos aspectos relevantes do problema enfocado pela pesquisa (Bruyne et al., 1977).

No processo da pesquisa, a elaboração de uma lista de variáveis consideradas caraterísticas do objeto pode ser considerada um primeiro passo. Como ela tende a ser normalmente ampla, apesar de sempre incompleta, muitas vezes usando categorias vagas e abstratas, e em geral agrupando um conjunto heterogêneo de fatores, em um segundo passo do trabalho ela precisa ser refeita. Classificações mais extensivas, referentes a um número elevado de atributos que são teoricamente considerados como variando quantitativa e qualitativamente entre diferentes momentos e/ou 
espaços, fornecem um quadro de análise que permite ordenar e por em correlação os atributos fixados. A análise multidimensional permite uma melhor apreensão do problema; a dimensão temporal propicia o estudo dos processos e das variações.

No sentido também de recortar e viabilizar este tipo de estudo, achamos interessante aprofundar a análise sobre a assistência a determinadas condições. Se as formas de entrada poderiam ser muitas - concepção da doença, aspectos da anamnese, exames subsidiários, recursos terapêuticos, relação médico-paciente - optamos por tomar como núcleo de análise a doença porque, de um lado, ela é a conformação de determinado problema no campo da saúde referente ao modo de vida; de outro, ela é objeto de práticas socialmente determinadas. A doença tomada então como estratégia metodológica de pesquisa, permite identificar, mais do que os meios $e$ instrumentos técnicos isolados, os determinantes e os valores que explicam as variações históricas da Medicina (Ayres, 1994). Nesta pesquisa

procuramos como doenças-índice algumas afecções que adquiriram variados significados no período estudado, tanto na concepção dos seus

determinantes, como na forma de ser diagnosticada e tratada. Entre as que preenchem estas características na segunda metade do século $\mathrm{XX}$, destacamos a úlcera gastroduodenal (Arquiola et al., 1987) e a hipertensão arterial (Hart, 1987; Hickey \& Graham, 1988).

A metodologia utilizada foi a de elaborar padrões para cada subperíodo $e$ compará-los, detectando tensões entre formas diferentes (contrastadas com as anteriores) de conceber e atuar na doença, que evidenciam os embates, as características históricas e sociais dos conhecimentos e da prática médica. A comparação de momentos sucessivos permite identificar alternativas de tendências, isto é, o sentido do que permanece (e do seu reverso, do potencial que não se mantém hegemônico, mas que pode retornar em outros futuros, com o mesmo significado, ou um outro, porque responde a necessidades colocadas).

\section{Transformações nas orientações para a boa prática em Medicina na segunda metade do século $\mathrm{XX}$}

Vamos estar aqui apresentando somente alguns aspectos das transformações da técnica em Medicina, e de forma relativamente breve, com o intuito menos de fornecer informações, e mais de dar ao leitor a oportunidade de conhecer o quadro teórico referencial na sua aplicação a um objeto, as agruras e soluções metodológicas e de dialogar com as idéias que desenvolvemos. É nosso objetivo maior estimular o leitor a pensar, para a sua própria área de atuação, sobre as relações entre passado, presente e futuro, e sobre como levantar dados para delinear tendências e identificar brechas de transformação.

Estudando-se as orientações para a prática dos médicos dos anos cinquenta, setenta e noventa, de uma forma mais geral, pudemos acompanhar um processo de localização da doença no corpo, objetivação do diagnóstico, tecnicização da relação médico-paciente, ampliação da intervenção, racionalização e matematização dos critérios e procedimentos, busca de simplificação da concepção de doença e da terapêutica, 
mercantilização da prática, centralização das decisões e controle do trabalho do médico.

Se já havíamos identificado algumas destas características na segunda metade do século XIX, constatamos que o padrão "localização, objetivação $e$ intervenção" se manteve, mas também se acentuou ao longo do século XX: a genética e os receptores viscerais fazem parte da tendência de localização da doença no corpo; a prova da doença através de exames subsidiários e a quantificação de parâmetros vitais representam objetivações do diagnóstico; a valorização da intervenção, incluindo as medidas preventivas, $e$ a terapêutica medicamentosa alinham-se com o movimento de

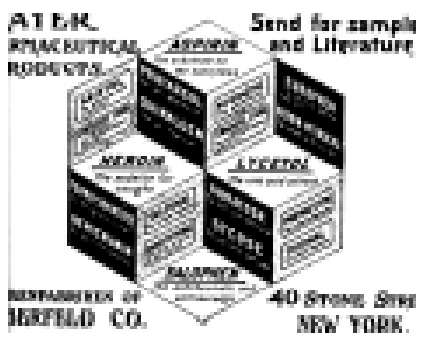
contraposição à evolução natural da doença. Entre os anos 50 e 90 deslocam-se os atributos valorizados no desempenho do médico da dimensão pessoal, humana e ética, para a da técnica, da perícia, da habilidade instrumental, do uso de equipamentos, da inovação, da autoridade do conhecimento especializado (Schraiber, 1997).

Por exemplo, em uma leitura mais linear das características da Medicina no período estudado podemos verificar as seguintes tendências: a concepção de doença passa da lesão ao risco e à anomalia, da qualidade à quantidade, da doença específica à síndrome/ao problema, do emocional ao visceral. $\mathrm{O}$ conhecimento epidemiológico e o clínico ganham legitimidade contribuindo de forma significativa para a apreensão da doença e para avaliar e legitimar as formas de diagnóstico e terapêutica. A incerteza, identificada como inerente à Medicina e ao caso individual, é aparentemente controlada pelo estudo da série e o cálculo de probabilidades, procedimentos que têm na Matemática sua base teórica e de aceitação social. A preocupação com o acerto do diagnóstico (preciso) e com o bem-estar e apoio ao paciente é relativamente deslocada pela preocupação com custos e resultados.

Fazendo uma leitura das tensões podemos identificar os embates, em que cada alternativa está vinculada a questões sociais mais amplas, como a relação do homem com a natureza, o significado da saúde/doença, da vida/ morte, a concepção de corpo e de indivíduo, as formas de cuidado. Tomando como exemplo a variação da concepção de doença - da lesão/ complicação ao risco - esta mudança não é conseqüência direta e exclusiva do conhecimento acumulado, mas dos valores sociais. Entre 1950 e 70 pode-se reconhecer uma variação não só do significado da vida, em que a convivência com situação de perigo torna-se indesejável, mas também uma ampliação do campo da Medicina que, além do paciente sintomático, passa a tomar como objeto aquele no qual identifica condição de risco. Entre os anos 70 e 90 acompanha-se ainda um estreitamento da faixa de normalidade, isto é, daquilo que se considera (socialmente) admissível em termos de risco (Kenen, 1996). Ao mesmo tempo, o cuidado se distancia do indivíduo singular e passa-se a considerar o paciente mais abstraído em uma série de indivíduos semelhantes que tiveram determinados resultados com tal ou qual procedimento. Entre as formas de cuidado, se em 1950 recomendavase ao paciente umas férias, uma pescaria, nos anos 90 controla-se o desempenho cardiovascular no exercício aeróbio. Ou seja, constata-se que as medidas mais gerais relacionadas com o comportamento foram 
quantificadas e padronizadas.

Segundo Granger (1994), desde o final do século XVII tem havido uma aproximação entre ciência e técnica, com desenvolvimento expressivo das técnicas baseadas em explicações científicas em comparação com aquelas que derivam seu conhecimento da experiência. Se a penetração da técnica pela ciência foi maior a partir da grande Revolução Industrial européia (XVIII), a Segunda Guerra Mundial - com as necessidades técnicas dos países beligerantes, o financiamento de pesquisa com dinheiro público e a constituição de pesquisadores profissionais - representa o marco inicial do que este autor denomina de "Idade da Ciência", tão grande e legitimada a sua dominância.

Esta associação mais estreita entre técnica e ciência confere características específicas a ambas. De um lado destaca-se o caráter aplicado da ciência contemporânea. De outro, se a técnica não impregnada pela ciência estava baseada no trabalho mais artesanal, transmitido em receitas $e$ manhas, e produzia obras individualizadas, a sua penetração pela ciência a modifica substancialmente. Uma das condições de aplicação da ciência é a redução dos objetos a esquemas abstratos - o despojamento dos fatos de condições históricas singulares que os co-determinam - $e$ a normalização do trabalho para diminuir custos, possibilitar o controle e aumentar a produção (Granger, 1994). O progresso técnico aumenta, nesta redução, a capacidade de intervenção e predição. É também claro que se trata de um tipo de predição, na qual, como se verá adiante, a incerteza não é banida.

No começo deste estudo, sabíamos que a Clínica não havia passado por uma revolução no período abrangido pela pesquisa, mas que, após a Segunda Guerra Mundial, houve uma maior penetração da técnica pela ciência (Granger, 1994). A análise das modificações dos seus componentes básicos - da concepção de doença, do diagnosticar e tratar - e dos seus elementos organizacionais complementares faz ver que tais variações foram profundas $e$ até radicais.

Entre 1950 e 90, pôde-se identificar a seguinte transformação da técnica em Medicina: da concepção de doença-lesão, da incerteza do conhecimento e da prática, da valorização da experiência clínica pessoal e da autonomia técnica do médico (Schraiber, 1988), para, respectivamente, a concepção de doença-risco (Kenen, 1996), o cálculo da probabilidade, a busca do respaldo científico e a medida dos resultados dos procedimentos.

Nessa transformação identifica-se mais do que uma modificação de quantidades ou um acréscimo de novas ordens, mas, uma variação de qualidades. Como pôde ser constatado, as modificações de substância da

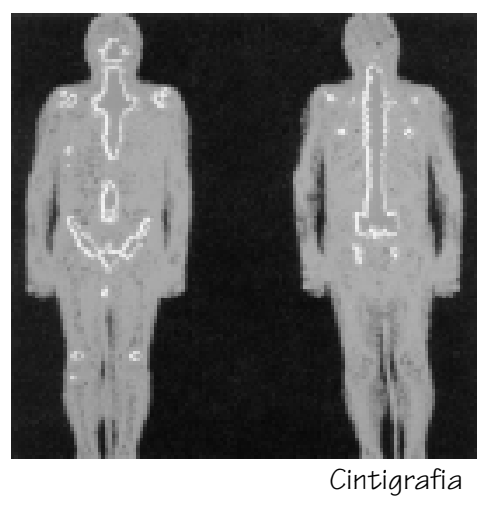


Clínica no decorrer da segunda metade do século XX não se deveram tanto a avanços internos da Medicina, como os não menos importantes e inúmeros desenvolvimentos nas áreas de microbiologia, genética, farmacologia, mas à aplicação à Medicina de conhecimentos científicos e técnicos desenvolvidos e usados em outras áreas e que, por legitimidade social dos valores que eles carregam e produzem, transferidos e adaptados à área da saúde. Portanto, um dos resultados deste tipo de estudo é a identificação de padrões da Clínica como tecnologia bastante distintos entre os anos 50 e 90, sendo a década de 1970 menos uma intermediária, do que um período com sua própria especificidade, entre as quais a preocupação com custos e a incorporação do risco como um problema para a assistência médica.

Vamos aqui sintetizar as bases e opções metodológicas que consideramos possam interessar a outros estudos sobre transformações de práticas sociais. Quando iniciamos este trabalho, partimos de uma configuração geral da Clínica no século XX, produto de outros estudos neste campo, que serviu de base para o levantamento $e$ a análise dos dados. Em vez de um conhecimento realista, impossível na abrangência "total" do objeto, na reconstrução da história produzimos um conhecimento parcial, de alguns pontos de vista, correspondente a faces do cubo (Veyne, 1983). Em vez da noção de desvelamento, produzimos conhecimento histórico, resultante de uma prática científica e social (De Certeau, 1982). Mais do que descrever os elementos da Clínica no período estudado, buscamos enunciar seu sentido, na articulação entre os elementos e do conjunto com as finalidades da Medicina no período; trabalhamos menos sobre o real do que sobre o inteligível (De Certeau, 1982). Supusemos no início que a Clínica, na segunda metade do século XX, tem especificidades que mereciam ser melhor conhecidas e arquitetamos uma estratégia teórica e metodológica para estudá-las. Se pessoalmente temos um certo interesse no passado, uma curiosidade pela forma de pensar e expressar, pelos costumes e fatos (e fitas $e$ fotos), conhecê-lo melhor pode nos inspirar a lidar com questões atuais. Conforme o referencial teórico adotado, a reconstrução histórica foi feita pela suspensão das categorias do presente, realizada pela problematização dos valores e conhecimentos, o que possibilitou a apreensão (parcial) de outras categorias (Loraux, 1992). Para além de encontrar precursores $e$ insuficiências, obstáculos e progressos, pudemos verificar a articulação $e$ tensão entre diversos componentes da Medicina e o sentido da sua variação, sendo que os resultados deste tipo de estudo são relativos e não categóricos.

O pressuposto teórico-metodológico de não reduzir a Medicina a um ou outro elemento, mas considerá-la no seu conjunto - a conformação do objeto ao qual ela se aplica, os meios de trabalho que ela utiliza para operar, o tipo e significados do seu produto, a forma de organizar a assistência (Donnangelo, 1979) - mostrou-se muito acertado e rico. Vale aqui mais uma vez lembrar que o modelo de interpretação é sempre elaborado no $e$ com as necessidades do presente. Se hoje o respaldo científico da prática é uma questão candente, fomos buscar no passado as indicações da base da prática e encontramos a valorização da tradição e da observação pessoal, da experiência clínica do médico (Molinder, 1995), e uma desconfiança dos resultados estatísticos. Encontramos, em vez do acúmulo de novos conhecimentos científicos, uma revisão de conteúdos, adequando-os às 
necessidades (sociais). Se podemos retomamos fatos esquecidos na história certamente sobre outros nada somos capazes de dizer.

Ao mesmo tempo que se produz o objeto da pesquisa precisamos representá-lo, ou seja, ele não existe sem assumir uma determinada forma, sem ter estabelecida uma rede de relações (Bruyne et al., 1977). Neste estudo trabalhou-se com critérios desenvolvidos no processo da pesquisa, $o$ sentido produzido ao final; o modelo que se quis delinear é apenas um momento técnico ou figura ideal da problemática, tendo uma estruturação provisória do sentido. Os padrões normativos da Clínica que identificamos em cada período e a formalização do conjunto como tecnologia, buscam integrar os elementos em uma unidade coerente, tendo como referência a teoria que orientou os critérios dos diversos cortes e recortes e a rearticulação dos elementos, de modo que nesta etapa do estudo pudéssemos propor uma interpretação da realidade. Nosso esforço foi o de conhecer o padrão de processos da (e na) Medicina (Veyne, 1983).

Do conjunto de informações disponíveis sobre o assunto, colhemos aquelas que julgamos pertinentes e que pudessem confirmar as hipóteses. Entre as limitações deste tipo de estudo, sabemos que nem tudo o que é importante para o tema foi escrito e o que foi registrado nem sempre foi publicado; portanto, sabe-se que na franja desta história há muitos outros conceitos, recursos, resultados e racionalidades do que puderam ser verificados. Ou seja, trabalhou-se com a produção "vencedora", considerada em cada período como as indicações para a boa prática.

O estudo comparativo do padrão da Clínica nos três períodos estudados permite ultrapassar o caso singular - da hipertensão, da úlcera, do tratado médico, da revista científica, do autor - possibilitando a constituição de regularidades (sintéticas) entre os vários momentos, podendo-se analisar semelhanças e dessemelhanças. As comparações no tempo permitem estudar os próprios processos de mudança em suas diversas fases interdependentes.

Cabe ainda uma última consideração, acerca da Clínica como tecnologia, não daquela faceta restrita aos recursos materiais, mas daquela, segundo Kneller (1980), que envolve um conjunto de elementos - agentes, instituições, produtos, conhecimentos e técnicas, e daquele ângulo proposto por Mendes-Gonçalves (1986), dos nexos técnicos estabelecidos no interior do processo de trabalho entre os elementos articulados às finalidades. No plano das indicações para uma boa prática, pudemos verificar não só a articulação entre os elementos, e de uma gama variada deles, mas também da sua variação histórica. Encontramos nos textos, integrados na orientações do modo de fazer, a concepção de objeto - doença e paciente, os meios de diagnóstico e tratamento, o papel esperado do médico e as articulações sociais da Medicina.

Reconhecer características e articulações do conjunto de elementos que compõe a assistência ao doente pode contribuir para entendê-la como tecnologia de trabalho, identificando contradições e tornando relativo o mito da prestação de serviços na "forma-ciência", tomada como preceito de escolha e de ação, que obscurece as dimensões sociais, psicológicas, biológicas, éticas e humanas da Medicina. Esperamos também ter trazido novos aportes para a análise de transformações em práticas sociais $e$ inspirado o leitor a fazer perguntas para o passado visando ao futuro. 


\section{Referências bibliográficas}

ARQUIOLA, E., GARCÍA-GUERRA, D., MONTIEL, L. La úlcera gastroduodenal: historia de una enfermidad. Barcelona: Ediciones Doyma, 1987.

AUTRET, M. Transfert de technologies du monde spatial vers le monde medical. Ann. Chir., v.50, n.2, p.159-61, 1996.

AYRES, J.R. Prefácio da edição brasileira. In: ROSEN, G. Uma história da Saúde Pública. São Paulo: Hucitec, Editora Unesp/Rio de Janeiro: Associação Brasileira de Pós-Graduação em Saúde Coletiva, 1994, p.19-26.

BRUYNE, P., HERMAN, J., SCHOUTHEETE, M. Dinâmica da pesquisa em ciências sociais. 3.ed. Rio de Janeiro: Francisco Alves, 1977.

CANGUILHEM, G. Ideologia e racionalidade nas ciências da vida. Lisboa: Edições 70, 1977.

CANGUILHEM, G. O normal e o patológico. 2.ed. Rio de Janeiro: Forense Universitária, 1982.

CID, F. Breve historia de las ciencias medicas. 2.ed. Barcelona: ESPAXS S.A., 1985.

DALMASO, A.S.W. Estruturação e transformação da prática médica: estudo de algumas características do modelo de trabalho médico na segunda metade do século XIX e início do século XX. São Paulo, 1991. 332p. Dissertação (Mestrado). Faculdade de Medicina, Universidade de São Paulo.

DALMASO, A.S.W. Estruturação e transformação da prática médica: técnica e ciência na segunda metade do século XX. São Paulo, 1998. 273p. Tese (Doutorado). Faculdade de Medicina, Universidade de São Paulo.

DAVIS, A.B. Historical studies of medical instruments. Hist. Sci., v.16, p.107-33, 1978.

DE CERTEAU, M. A escrita da história. Rio de Janeiro: Forense, 1982.

DONNANGELO, M.C.F. Saúde e sociedade. In: DONNANGELO, M.C.F.; PEREIRA, L. Saúde e sociedade. 2.ed. São Paulo: Duas Cidades, 1979. p.11-94.

DUSTAN, H.P. Hypertension revisited after 55 years: how it has changed! Am. J. Med. Sci., v.309, n.2, p.69-70, 1997.

ENTRALGO, P.L. Historia de la medicina. Barcelona: Salvat, 1978.

FERNANDES, F. Fundamentos empíricos da explicação sociológica. São Paulo: Companhia Editora Nacional, 1959.

FOUCAULT, M. O nascimento da clínica. Rio de Janeiro: Forense-Universitária, 1977.

FROHLICH, E.D. The sixth report of the Joint National Committee, an appropriate celebration of the 25th anniversary of the National High Blood Pressure Education Program. Hypertension, v.30, p.1305-06, 1997.

GRANGER, G.G. A ciência e as ciências. São Paulo: Editora Unesp, 1994.

GRAVES, R.J. Leçons de clinique médicale. Paris: Delahaye, 1862.

HART, J.T. Hypertension: community control of high blood pressure. 2.ed. Edinburgh: Churchill Livingstone, 1987.

HICKEY, N., GRAHAM, I.M. Hypertension. London: Croom Helm, 1988.

JACCOUD, S. Leçons de clinique médicale faites a l'Hopital de la Charité. 2.ed. Paris: Delahaye, 1869. KENEN, R.H. The at-risk health status and technology: a diagnostic invitation and the "gift" of knowing. Soc. Sci. Med., v.42, n.11, p.1545-53, 1996.

KNELLER, G.F. A ciência como atividade humana. Rio de Janeiro: Zahar/ São Paulo: EDUSP, 1980. cap.11, p.245-70. (Ciência e tecnologia).

LOGAN, R.L., SCOTT, P.J. Uncertainty in clinical practice: implications for quality and costs of health care. Lancet, v.347, p.595-8, 1996.

LORAUX, N. Elogio do anacronismo. In: NOVAES, A.(Ed.) Tempo e história. São Paulo: Secretaria Municipal de Cultura/Companhia das Letras, 1992. p.57-70.

MENDES-GONÇALVES, R.B. Medicina e história. Raízes sociais do trabalho médico. São Paulo, 1979. 209p. Dissertação (Mestrado). Faculdade de Medicina, Universidade de São Paulo.

MENDES-GONÇALVES, R.B. Tecnologia e organização social das práticas de saúde: características 
do processo de trabalho na rede estadual de centros de saúde de São Paulo. São Paulo, 1986. 416p. Tese (Doutorado) - Faculdade de Medicina, Universidade de São Paulo.

MENDES-GONÇALVES, R.B. Tecnologia e organização social das práticas de saúde: características do processo de trabalho na rede estadual de centros de saúde de São Paulo. São Paulo: Hucitec/Rio de Janeiro: Abrasco, 1997.

MENDES-GONÇALVES, R.B. Práticas de saúde: processos de trabalho e necessidades. CAD. CEFOR, n.1, 1992 (Cefor/ SMS. Série Textos).

MOLINDER, H.K. Scandinavian views on the non-surgical treatment of peptic ulcers, 1940-1975: rationales for recommendations and results. Scand. J. Gastoenterol., v.30, p.721-30, 1995.

NOVAES, R.L. Sobre a técnica. Hist., Ciênc., Saúde - Manguinhos, v.3, n.1, p.24-49, 1996.

ORTEGA Y GASSET. Meditação da técnica. Rio de Janeiro: Livro Íbero-americano Ltda, 1963 apud RIBEIRO, J.M. Trabalho Médico: ciência, arte e ação na conformação da técnica. Rio de Janeiro, 1995. p.127-40.

Tese (Doutorado). Escola Nacional de Saúde Pública, Fundação Oswaldo Cruz.

REISER, S.J. La medicina y el imperio de la tecnologia. Mexico: Biblioteca de la Salud, 1990.

RIBEIRO, J.M. Trabalho médico: ciência, arte e ação na conformação da técnica. Rio de Janeiro, 1995. 590p.

Tese (Doutorado). Escola Nacional de Saúde Pública, Fundação Oswaldo Cruz.

SACKETT, D.L.et al. Evidence-based Medicine: how to practice and teach EBM. New York: Churchill Livingstone, 1997.

SCHRAIBER, L.B. Medicina liberal e incorporação de tecnologia: as transformações históricas da autonomia profissional dos médicos em São Paulo. São Paulo, 1988. 391p. Tese (Doutorado). Faculdade de Medicina, Universidade de São Paulo.

SCHRAIBER, L.B. Educação médica e capitalismo: um estudo das relações educação e prática médica na ordem social capitalista. São Paulo: Hucitec/Rio de Janeiro: Abrasco, 1989.

SCHRAIBER, L.B. Medicina tecnológica e prática profissional contemporânea: novos desafios, outros dilemas. São Paulo, 1997. 209p. Tese (Livre-docência). Faculdade de Medicina, Universidade de São Paulo. VEYNE, P. Como se escreve a história. Lisboa: Edições 70, 1983.

DALMASO, A. S. W. Análisis de las transformaciones de la técnica en Medicina: reflexiones acerca de una propuesta metodologica, Interface _ Comunicação, Saúde, Educação, v.4 , n.6, 2000.

Este texto trata de la conformación de la medicina contemporánea como práctica histórica y social, cuya técnica está siendo crecientemente penetrada, no sólo por el conocimiento, sino también por la racionalidad científica. El ángulo escogido para entender esta articulación fue el de las orientaciones para la buena práctica. A través de las informaciones obtenidas en ediciones y publicaciones de tratados médicos y revistas científicas consagradas, escritas en la segunda mitad del siglo XX , se delineó el modelo de transición de la práctica clínica en el período. La comparación entre épocas (años 50, 70 y 90) hizo posible el reconocimiento de un movimiento de procesos, con diversas tensiones en relación a las indicaciones para el buen desempeño del médico. En lo que se refiere a las orientaciones para la práctica de la medicina, fue constatada una variación técnica importante, caracterizada por los cambios en la experiencia clínica personal y por la producción relativamente diseminada de la investigación asociada a la atención médica, para la valorización de los procedimientos científicamente respaldados, sometidos a pruebas de eficacia y de resultados, y para la ampliación de los centros especializados en investigación. La clínica, técnica desarrollada en la cercanía del enfermo y del arte, trabajo operacional y singular, que aplica la ciencia en la atención médica individual, y está comprometida con la acción, ha sido y continua siendo progresivamente direccionada para la práctica de procedimientos más teóricos y científicos.

PALABRAS-CLAVE: historia de la medicina del siglo 20; tecnología médica; conocimientos; actitudes; prácticas; prácticas professionales 